\title{
Massive bleeding following severe blunt trauma: the first minutes that can change everything
}

\section{Martin Lucien Tonglet, Patrick Greiffenstein, Francois Pitance \& Stephane Degesves}

To cite this article: Martin Lucien Tonglet, Patrick Greiffenstein, Francois Pitance \& Stephane Degesves (2016) Massive bleeding following severe blunt trauma: the first minutes that can change everything, Acta Chirurgica Belgica, 116:1, 11-15, DOI: 10.1080/00015458.2015.1136488

To link to this article: http://dx.doi.org/10.1080/00015458.2015.1136488

Accepted author version posted online: 12

Jan 2016.

Published online: 20 Apr 2016.

Submit your article to this journal $\pi$

Џ Article views: 11

View related articles

View Crossmark data \lceil 
REVIEW PAPER

\title{
Massive bleeding following severe blunt trauma: the first minutes that can change everything
}

\author{
Martin Lucien Tonglet ${ }^{\mathrm{a}}$, Patrick Greiffenstein ${ }^{\mathrm{b}}$, Francois Pitance ${ }^{\mathrm{c}}$ and Stephane Degesves ${ }^{\mathrm{a}}$ \\ ${ }^{a}$ Department of Emergency, CHR De La Citadelle, Liege, Belgium; ${ }^{\mathrm{b}}$ Trauma Unit, Louisiana State University Medical Center, \\ New Orleans, LA, USA, 'Anesthesiology and Intensive Care Unit, CHR De La Citadelle, Liege, Belgium
}

ABSTRACT

The first hour following a major trauma with massive bleeding is certainly the most decisive period in global trauma care. Most of it takes place during the prehospital care. Those prehospital minutes are thus determinant as they can be used to correctly identified patient's clinical condition, initiate organization of the in-hospital needed resources and initiate specific therapies in the very early phase after trauma. Significant recent advances in this aspect of care have been made and but evidence to support some of those strategies is still lacking.

\section{KEYWORDS}

Hemorrhage; prehospital care; transfusion
The management of severe trauma patients is one of the biggest challenges that prehospital care providers can face. A meta-analysis of United States trauma centers demonstrated average prehospital times from injury to hospital admission about $30 \mathrm{~min}$ for road ambulances and over $60 \mathrm{~min}$ for helicopter transports.[1] Most of the "golden-hour" thus sometimes takes place during the prehospital care, making this phase of care essential.[2] Prehospital delay, however, varies depending on geographical situation (urban versus rural areas) and depending of the local health system. Prehospital delays are shorter in Europe and in our country.

For the past years, several approaches have been proposed in order to increase the quality of care. A large part of the care concerns evacuation of the patient, their extraction from a vehicle, management of cervical spine immobilization, airway management, and other topics that would not be discussed here.

We will focus on the management of the massively bleeding trauma patients and on the many significant recent advances in this aspect of care. Historically, several strategies have been proposed and used for prehospital management of massively bleeding trauma patients. Many of those have been developed in the military setting and adapted in civilian trauma centers. They all aim to help the prehospital caregivers to face this life-threatening situation with very high mortality.

\section{We should scoop and run...}

In most cases of massive exsanguination, emergent open or endovascular procedures are necessary for hemostasis such that this cannot be achieved anywhere else but at the hospital. For this group of patients, minimizing prehospital time and ensuring rapid transport to the nearest facility is life-saving. However, not all facilities provide the technology, human resources, training, and expertise to perform the necessary procedures. Designation of receiving hospitals within regional trauma systems has been clearly demonstrated to have a positive impact on patient mortality and morbidity.[3,4] Thus, it is important that the patient be transported to the appropriate facility to ensure the best outcome, even if it is not the nearest.

\section{We should stay and play...}

Advanced Life Support (ALS) trained providers are capable of performing more invasive procedures than Basic Life Support (BLS) providers which, on the face of it, would seem beneficial in the care of critically injured patients. However, several studies have shown that, in certain settings, this seems to have little impact on patients' outcome. Liberman et al. [5] showed, in their multicenter Canadian study, that there was no benefit in having on-site ALS providers in urban areas with level-one trauma centers. Seamon et al. [6] demonstrated the same

CONTACT Martin Lucien Tonglet, MD tongletm@yahoo.com $\mathrm{E}$ Department of Emergency, CHR de la Citadelle, Boulevard du 12eme de Ligne, 1 4000 Liege, Belgium

(C) 2016 The Royal Belgian Society for Surgery. 
results for the management of penetrating trauma patients in an urban area with short transport times (global prehospital time was the same for BLS or ALS but ALS interventions did not improve patients' outcome). Other studies in other context clearly demonstrated better outcome with ALS.[7] ALS and BLS are part of a global prehospital system and their impact cannot be analyzed without their context.

\section{We should treat as we go...}

Another approach to prehospital care is the "treat as you go" philosophy described in the Prehospital Trauma Life Support PHTLS manual.[8] In the presence of a severely injured trauma patient, prehospital care givers are admonished to only perform lifesaving emergent procedures, such as securing an airway, providing oxygen, needle decompression of tension pneumothorax, cervical spine immobilization, pelvic binding, and splinting of extremities, and try to do them without delaying transportation to the hospital by performing a rapid on-site clinical evaluation and then performing those therapeutic actions during transportation whenever possible.

\section{We should give fluids...}

Massively bleeding patients suffer from hypovolemic shock that, if left uncorrected for too long, will become irreversible. Early and aggressive fluid resuscitation using crystalloids solution was the preferred first step in the management dating back to World War II. Significant improvements in triage and battlefield transport during the Vietnam War meant that more severe injuries were being treated and transported than ever before. This also meant that casualties were receiving large amounts of crystalloids during the first hours of care and, when compared with previous conflicts, it was clear that many lives were saved from lethal hypovolemia with aggressive fluid resuscitation. At the same time, an interesting clinical phenomenon was first described and was initially referred to as Da-Nang Lung, named for the military base where these casualties were collected prior to transfer to tertiary care centers outside the theatre of war. These were patients who, despite having suffered no pulmonary or thoracic injury, rapidly developed severe acute respiratory distress within the first few days of care.[9] This pulmonary edema was suspected to be the result of alveolar lesions caused by explosive shock waves but some recognized the possibility that this was related to volume overload due to the unrestrictive fluid therapy.

Other adverse effects of intravenous fluid therapy are the dilution of coagulation factors that have been lost during exsanguination and that have a predictably negative impact on coagulation. This effect has been demonstrated in vitro as well as in vivo.[10,11] Additionally, unless appropriately warmed, large infusions of fluid will profoundly exacerbate the hypothermia that is present in many trauma patients and, thus, plays a pivotal role in what was called the "lethal triad": the triple association of acidosis, hypothermia, and coagulopathy which was pointed out as having a significant negative impact on patients' survival after severe trauma.[11]

\section{We should restrict our fluid therapy...}

Restriction of fluid resuscitation implies recognition of the negative consequences of fluid therapy and the need to minimize these in the process of caring for the severely injured. This has led to the development of what is called damage control resuscitation, or the idea that early treatment of patients massively exsanguinating should revolve around three things: limiting the use of crystalloids, liberal use of blood products in an equivalent ratio of blood and plasma, and allowing for permissive hypotension until definitive surgical hemostasis can be achieved.[12,13] This strategy was first postulated by the father of modern resuscitation, the great American physiologist Walter Cannon as far back as 1910 and has been relatively ignored for nearly a century.[14] It should be noted that permissive hypotension should not be utilized in the setting of known or suspected traumatic brain injury (TBI) to avoid secondary brain injury due to hypoperfusion.

\section{We should stop the bleeding...}

The treatment of bleeding is to stop the bleeding. Trauma patients in need of emergency surgery for ongoing hemorrhage have increased survival if the elapsed time between injury and admission to the operating theatre is minimized.[15] Some haemostatic procedures might be indicated during the prehospital stage before or during transportation to the hospital. Clearly, any severe external bleeding source can and should be controlled with either point-pressure or tourniquet placement immediately. Unstable pelvic ring fracture should lead to minimized mobilization and external stabilization 
using sheets or pelvic sling. Pelvic ring fractures with hemodynamic compromise sometimes need an invasive control of the internal bleeding. This can be accomplished within the hospital with interventional radiology.

\section{We should transfuse the patient with blood products in the hospital. . .}

Every massively bleeding patient requires transfusion of blood components, including packed red blood cells (PRBC), plasma, and platelets. Although the ideal ratio of components is still under debate, balanced transfusion therapy is inarguably the cornerstone of resuscitation in massive exsanguination. As an emergent transfusion of sufficient blood components requires an appropriate infrastructure and time for preparation, prehospital caregivers should transport patient towards an appropriate facility. In-hospital transfusion team could be alerted before patient's admission using prehospital clinical judgment from care givers or using prehospital-specific scoring systems like the Coagulopathy of Severe Trauma score COAST or the Trauma Induced Coagulopathy Clinical Score TICCS, developed to identify trauma patients suffering from massive bleeding and in need for transfusion.[16,17] Identification of patients in need for massive transfusion is critical because it cannot be applied to patients with moderate bleeding as it will have a negative impact with higher risk for infections, for thromboembolic events or for specific respiratory failures like Transfusion Related Acute lung Injury or Transfusion Associated Cardiac Overload.

\section{We should transfuse the patient with blood products during transportation...}

Recent data suggest that despite our efforts, in the context of level-one trauma centers areas with inhospital emergent surgery and massive transfusion of blood products, we still are partly ineffective on correction of both hypoperfusion and coagulopathy.[18] We know that the early acute coagulopathy starts shortly after trauma.[19] We know that massive bleeding quickly leads to hypoperfusion and shock. Does it mean that we should transfuse earlier, by carrying blood products in the prehospital setting? Recent experiences in the military and the civilian settings concerning PRBC prehospital transfusion highlighted the feasibility of such a practice and its potential positive impact.[20-22] The on-going PAMPER trial (Prehospital Air Medical
Plasma Trial) will determine the effect of the prehospital infusion during air transport of 2 units of plasma on $30 \mathrm{~d}$ mortality in patients with hemorrhagic shock as compared with conventional care.[23] Previous studies emphasized the positive impact of an early plasma transfusion in massive hemorrhage.[24] Prehospital transfusion, however, needs to be considered in the global context of care and would be, thus, more interesting and rural areas with delayed prehospital time, rather than in urban Belgian areas with short delay before hospital admission.

\section{We should detect early acute coagulopathy...}

As the early acute coagulopathy of trauma begins in the very early phase after severe trauma,[19] an early detection of this coagulopathy is needed and could lead to potential therapeutic actions to treat it, especially when prehospital delays are prolonged. Careful selection of trauma patients suffering from severe bleeding and acute coagulopathy is challenging and essential because of the potential therapeutic implications. Conventional coagulation laboratory tests need time to be performed. Thromboelastographic assays have been recently highlighted as an alternative option to detect acute coagulopathy shortly after trauma and their results are quickly available.[25,26] Prehospital use of point-of-care thromboelastographic analyses could be proposed but studies are needed to determine its impact [27] and its feasibility.[28] Prehospital recognition of coagulopathy in trauma patients could be performed using prehospital clinical scores like COAST [16] or TICCS.[17]

\section{... and treat it with specific actions. .}

A prehospital detection of the early acute coagulopathy following severe trauma could lead to potential-specific therapeutic actions. Several studies demonstrated that severe trauma patients benefit from an early administration of an antifibrinolytic agent, like tranexamic acid.[29,30] The MATTERs study investigators went further by suggesting the association of a fibrinogen supplementation therapy (with cryoprecipitate) to the antifibrinolytic therapy and demonstrated a better outcome when the combined therapy was applied.[31]

\section{Future directions. . .}

Rapid Endovascular Balloon Occlusion of the Aorta REBOA has been recently suggested in the 
prehospital setting and could be studied as a potential part of our therapeutic armamentarium.[32-34]

Other novel methods of prehospital hemostasis in extreme circumstances are being explored. These include intraperitoneal injection of selfexpanding polyurethane polymer foam for noncompressible massive hemorrhage as well as prehospital thoracotomy, although these methods are as yet of unproven efficacy.[35-37]

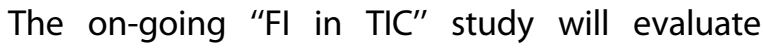
whether the prehospital pro-coagulant treatment with fibrinogen concentrate would improve plasmatic coagulation capacity in severe bleeding trauma [38] but until now there is no evidence encouraging the use of fibrinogen concentrate in massive bleeding. Regarding the prehospital administration of Prothrombin Complex Concentrate in the absence of a vitamin $\mathrm{K}$ antagonist therapy, data are still lacking.[39]

\section{Conclusion}

The first hour following a major trauma with massive bleeding is certainly the most decisive period in global trauma care. Depending of the context, most of it sometimes takes place in the prehospital setting where many of the needed supplies in terms of diagnosis, human resources, and treatment options are currently lacking in most trauma systems. But, far from being a loss of time, those precious minutes can be used by both the prehospital caregivers and the receiving hospital to initiate diagnosis and therapies that will have a significant positive impact on patient's outcome.

\section{Disclosure statement}

The authors report no conflicts of interest. The authors alone are responsible for the content and writing of this article.

\section{References}

[1] Carr B, Caplan J, Pryor J, et al. A meta-analysis of prehospital care times for trauma. Prehosp Emerg Care. 2006;10:298-306.

[2] Trunkey DD. Trauma care systems. Emerg Med Clin North Am. 1984;2(4):913-22.

[3] MacKenzie E, Rivara F, Jurkovich G, et al. A national evaluation of the effect of trauma-center care on mortality. N Engl J Med. 2006;354:366-378.

[4] Demetriades D, Martin M, Salim A, et al. The effect of trauma center designation and trauma volume on outcome in specific severe injuries. Ann Surg. 2005;242:512-517.
[5] Liberman M, Mulder D, Lavoie A, et al. Multicenter Canadian study of prehospital trauma care. Ann Surg. 2003;237:153-160.

[6] Seamon MJ, Doane SM, Gaughan JP, et al. Prehospital interventions for penetrating trauma victims: a prospective comparison between Advanced Life Support and Basic Life Support. Injury. 2013;44:634-638.

[7] Bakalos G, Mamali M, Komninos C, et al. Advanced life support versus basic life support in the pre-hospital setting: a meta-analysis. Resuscitation. 2011;82:1130-1137.

[8] Ali J, Adam RU, Gana TJ, et al. Effect of the prehospital trauma life support program (PHTLS) on prehospital trauma care. J Trauma. 1997;42:786-790.

[9] Fishman AP. Shock lung: a distinctive nonentity. Circulation. 1973;47:921-923.

[10] Treib J, Haas A, Pindur G. Coagulation disorders caused by hydroxyethyl starch. Thromb Haemost. 1997;78:974-983.

[11] Rotondo MF, Zonies DH. The damage control sequence and underlying logic. Surg Clin North Am. 1997;77:761-777.

[12] Dutton RP, Mackenzie CF, Scalea TM. Hypotensive resuscitation during active hemorrhage: impact on in-hospital mortality. J Trauma. 2002;52:1141-1146.

[13] Morrison CA, Carrick MM, Norman MA, et al. Hypotensive resuscitation strategy reduces transfusion requirements and severe postoperative coagulopathy in trauma patients with hemorrhagic shock: preliminary results of a randomized controlled trial. J Trauma. 2011;70:652-663.

[14] Cannon WB, Fraser J, Cowell EM. The preventive treatment of wound shock. JAMA. 1918;70:618-621.

[15] Spahn DR, Bouillon B, Cerny V, et al. Management of bleeding and coagulopathy following major trauma: an updated European guideline. Crit Care. 2013;17:R76.

[16] Mitra B, Cameron PA, Mori A, et al. Early prediction of acute traumatic coagulopathy. Resuscitation. 2011;82:1208-1213.

[17] Tonglet ML, Minon J, Seidel L, et al. Prehospital identification of trauma patients with early acute coagulopathy and massive bleeding: results of a prospective non-interventional clinical trial evaluating the Trauma Induced Coagulopathy Clinical score (TICCS). Crit Care. 2014;18:648.

[18] Khan S, Brohi K, Chana M, et al. Internation Trauma Research Network (INTRN). Hemostatic resuscitation is neither hemostatic nor resuscitative. J Trauma Acute Care Surg. 2014;76:561-567.

[19] Brohi K, Singh J, Heron M, et al. Acute traumatic coagulopathy. J Trauma. 2003;54:1127-1130.

[20] Brown JB, Sperry JL, Fombona A, et al. Pre-trauma center red blood cell transfusion is associated with improved early outcomes in air medical trauma patients. J Am Coll Surg. 2015;220:797-808

[21] Sherren PB, Burns B. Prehospital blood transfusion: 5year experience of an Australian helicopter emergency medical service. Crit Care 2013;17:P295.

[22] Weaver AE, Eshelby S, Norton J, et al. The introduction of on-scene blood transfusion in a civilian 
physician-led pre-hospital trauma service. Sci J Trauma Resusc Emerg Med. 2013;21:S27.

[23] Prehospital Air Medical Plasma Trial, NCT01818427

[24] Gonzalez EA, Moore FA, Holcomb JB, et al. Fresh frozen plasma should be given earlier to patients requiring massive transfusion. J Trauma. 2007;62:112-119.

[25] Holcomb JB, Minei KM, Scerbo ML, et al. Admission rapid thrombelastography can replace conventional coagulation tests in the emergency department: experience with 1974 consecutive trauma patients. Ann Surg. 2012;256:476-486.

[26] Cotton BA, Faz G, Hatch QM, et al. Rapid thromboelastography delivers real-time results that predict transfusion within 1 hour of admission. J Trauma. 2011;71:407-414.

[27] Hagemo JS. Prehospital detection of traumatic coagulopathy. Transfusion. 2013;53:48S-51S.

[28] Schott U. Prehospital coagulation monitoring of resuscitation with point-of-care devices. Shock. 2014;41:26-29.

[29] Shakur H, Roberts I, Caballero J. CRASH-2 trial collaborators, et al. Effects of tranexamic acid on death, vascular occlusive events and blood transfusion in trauma patients with significant haemorrhage (CRASH-2): a randomized, placebo-controlled trial. Lancet. 2010;376:23-32.

[30] Morrison JJ, Dubose JJ, Rasmussen TE, et al. Military application of tranexamic acid in trauma emergency resuscitation (MATTERs) study. Arch Surg. 2012;147:113-119.

[31] Morrison JJ, Ross JD, Dubose JJ, et al. Association of cryoprecipitate and tranexamic acid with improved survival following wartime injury: findings from the MATTERs II study. JAMA Surg. 2013;148:218-225.

[32] Andersen NG, Rehn M, Oropeza-Moe $M$, et al. Prehospital resuscitative balloon occlusion of the aorta. Scan J Trauma Resusc Emerg Med. 2014;22:P19.

[33] Morrison JJ, Ross JD, Rasmussen TE, et al. Resuscitative endovascular balloon occlusion of the aorta: a gap analysis of severely injured UK combat casualties. Shock 2014;41:388-393.

[34] Morrison JJ, Percival TJ, Markov NP, et al. Aortic balloon occlusion is effective in controlling pelvic hemorrhage. J Surg Res. 2012;177:341-347.

[35] Davies GE, Lockey DJ. Thirteen survivors of prehospital thoracotomy for penetrating trauma: a prehospital physician-performed resuscitation procedure that can yield good results. J Trauma. 2011;70:E75-E78.

[36] Duggan M, Rago A, Sharma U, et al. Self-expanding polyurethane polymer improves survival in a model of noncompressible massive abdominal hemorrhage. J Trauma Acute Care Surg. 2013;74:1462-1467.

[37] Rago AP, Larentzakis A, Marini J, et al. Efficacy of a prehospital self-expanding polyurethane foam for noncompressible hemorrhage under extreme operational conditions. J Trauma Acute Care Surg. 2015;78:324-329.

[38] Fibrinogen concentrate in trauma patients, presumed to bleed (FlinTIC). NCT01475344.

[39] Schochl H, Schlimp CJ, Maegele M. Tranexamic acid, fibrinogen concentrate and prothrombin complex concentrate: data to support prehospital use? Shock. 2014;41:44-46. 